\title{
Cracking the Snake Detection Theory: The Subcortical Visual Pathway as a Major Player in Cultural Transformations
}

\author{
Bogdan-Ioan Nicula \\ Independent Researcher, Bucharest, Romania \\ Email: fabianfucan@gmail.com
}

How to cite this paper: Nicula, B.-I. (2020) Cracking the Snake Detection Theory: The Subcortical Visual Pathway as a Major Player in Cultural Transformations. World Journal of Neuroscience, 10, 166-190.

https://doi.org/10.4236/wjns.2020.104018

Received: August 13, 2020

Accepted: November 6, 2020

Published: November 9, 2020

Copyright $\odot 2020$ by author(s) and Scientific Research Publishing Inc. This work is licensed under the Creative Commons Attribution International License (CC BY 4.0).

http://creativecommons.org/licenses/by/4.0/

\begin{abstract}
According to the proposed hypothesis, graphic characters trigger the subcortical visual route. The reaction discussed is very weak. Yet, its very existence has an unusual importance: characters and (occluded) venomous snakeskin patterns reveal themselves as conflatable. Furthermore, following tractographic research, a functional segregation of the subcortical pathway is to be presupposed. Thus, there can't be a later dissociation of two stimuli previously associated. The outcomes of lecture will gradually appear probabilistically (much) more peaceful than encountering a venomous snake, though, and thus a continuous lessening of the reaction is expectable. Here, on one hand, it is relevant that the subcortical visual pathway goes to the amygdala. The reactions we describe tap into goal-oriented processes, and they will do that unfettered. On the other hand, in the case of characters, since the beginning, fear has been converted into appetition to a great degree. This process should be fostered in the presence of light. In this way, luminosity might become a conditioned stimulus for attraction. In this case, a Pavlovian addiction for light will foster, yet also-from the point of view of reward feeling-counterbalance the lessening of the stimulation elicited by characters. The addiction we refer to is one towards light accompanied by graphic signs. Yet, as opposed to the case of the luminous medium, the attention captured by the later ones taken for themselves is continuously reduced.
\end{abstract}

\section{Keywords}

Active Inference, Blindsight, Delayed Detachment Hypothesis, Snake Detection Theory, Subcortical Route, V2 Area, V4 Area

\section{Introduction}

It was remarked that in learning the Devanägarī script by illiterate subjects, the 
following visual cortices were involved: V1, V2, V3, and V4 (all of them, right lateralization). Completely new in fMRI studies on reading (in general) was here the involvement of two areas of subcortical origin: the superior colliculus (right lateralization), and the pulvinar nuclei (bilaterally) [1]. Not intending to belittle a probable great importance pertaining to it, it seemed to us unnecessary to explore the issue of the lateralization. Instead, as it will be seen, we have paid more attention to the divisions of the pulvinar nuclei and to the visual patterns involved.

We employ here a "cracked" version of the Snake Detection Theory (SDT). The SDT central claim is that snakes had decisively shaped the visual systems of our ancestors, a hypothesis discouraged by current data [2]. We use SDT, although in a limited form. i.e. our assertion is that primates are "proficient" in locating snakes. Yet "proficient" should be taken cum grano salis in this context: usually, natural situations and laboratory conditions are different. The first ones seem to be much "nastier" in general [3]. Here, we should firmly distinguish between developing some kind of capacity and real life expertise.

According to Lynn A. Isbell, the "architect" of the original SDT, the V2 area is very important during phase one of snake detection. Together with some other cortical areas, V2 promptly participates in the first stage. For a reason that will be pointed out later on, i.e. the anatomical isolation of the subcortical visual pathway (at least) in humans, it may be safe to ignore the influence of these other cortical areas, when assembling our hypothesis. Also, following Isbell, V1 and $\mathrm{V} 4$ areas-together with some other cortical areas-are involved only in further processing. So, let us return to phase one. Here we would have, in fact, a blend of cortical and subcortical contributions. According to Isbell, the subcortical participants in the phase one are the superior colliculus, the pulvinar nuclei and the amygdala, all three united by a subcortical visual route, which is the secondary visual pathway in primates, yet the primary one in all the other vertebrates [4]. (Or, at least, in most of them.)

A classical evolutionary hypothesis says that visually degenerated fossorial lizards lay at the origins of modern snakes. It is supposed that the degeneration of the eyes was the occasion for a major reorganization of the visual system: in snakes too, the subcortical pathway went secondary [5] [6]. High-resolution ancestral cranial reconstructions impel us to recognize the ancestors of the modern snakes as terrestrial-or maximum semifossorial [7] [8]. Yet, a considerably weaker reliance on the subcortical route in snakes is an observation that stays on its own feet.

Recently, still supporting the fossorial hypothesis, the authors of a study argued that in an Australian lizard species with various intermediate forms, snakelike lizards penetrate better the sand substrates, compared with the usually shaped ones [9]. We can't exclude semifossoriality as a selective pressure prompting a common ancestor of snakes to go through the reorganization of the visual system [10], but this is not really our point in bringing the observation of this study 
on the table. It is rather that no matter the triggers for the transformation of their visual system, ancient snakes, by opting to remain terrestrial/turn back to the surface of the earth, are to be hailed as outstanding prophets. More exactly, as avoiders of a catastrophe. For snakes, yet not for lizards, fossoriality is indeed an evolutionary dead end [11]. So, the bound between the snake and the human invoked by our "cracked" version of SDT is not (necessarily) a very tight mutual prey-predator relationship. It is rather a case of (slightly) resembling convergent evolution [12] [13] [14], and, maybe, more than this. At a particular moment in their evolutionary biography, snakes were tapping into an improper niche, but finally, we will find (some of) them wise enough to avoid it. These snakes seem to have had acquired (the basis of) their visual system, almost unique by far. Primates, as we will show, know an evolutionary path that is symmetric. "Orienting" themselves towards the premises of a catastrophe represented by an addiction which threatens, in fact, not only with a dead end for their evolution, but with an ecological disaster that may lead to their extinction, and acquiring an inversed visual system "in due time".

As the visual peculiarity of primates has been brought into question, the same goes for the dogma of reading as integrally cortical. What our research brings new is the idea that the subcortical contribution to reading, the last one being taken quite in general, is more relevant than the cortical activity involved in the task. Coming back to the research itself, let us remark that out of six structures highlighted by Skeide and his colleagues [1], five play more or less important roles in the SDT. But, on one hand, SDT does not require a critical V3 involvement. On the other hand, and more importantly, it mustn't be overlooked that no report of amygdala activity is to be found in the named study.

\section{The Functionality and Structure of the Subcortical Visual Pathway in Humans}

\subsection{The Dorsal Region of the Lateral Pulvinar, Susceptible of Involvement in Reading}

Until very recently the functionality of the subcortical, or retino-tectal visual route in humans was controversial. Its functional nature now seems fairly grounded [15] [16] [17] [18]. As the pulvinar area is reportedly crossed by the subcortical path, the dorsal (or dorso-median) division of the pulvinar nuclei is a key element within the subcortical route [4] [16] [17] [18]. This division comprises the dorsal subdivision of the lateral pulvinar [19] [20].

While we can say that, concerning the visual system, the evolution of primates translates into less reliance on the superior colliculus [6], the expansion of the pulvinar along the evolution of the primates is comparable to the expansion of the prefrontal cortex [21]. Yet, not the whole pulvinar was majorly transformed in the process. The only part that has indeed changed a lot is the (dorso-)median pulvinar [4].

The dorsal (or dorso-median) pulvinar has attributions like attentional con- 
trol, temporal continuity and narrative interpretation of the visual events, thus it possesses a highly cognitive profile. The ventral pulvinar encodes moment-tomoment transitions, and also has a role in discriminating faces [22]. The dorso-median region of the pulvinar nuclei separates relevant clues from disturbing factors. The dorsal and the median part of the lateral pulvinar, areas associated with the secondary visual route, are particularly involved in this process of distinguishing specific features [23]. In the four cases examined in a study with tracers, this particular area was consistently identified as part of a functional subcortical visual pathway in macaques [24].

The assistance of the previously mentioned region of the lateral pulvinar in reading seems fairly reasonable. Yet, this subdivision should not be immediately identified as the recruited area from study made by Skeide and his colleagues [1]. The pulvinar nuclei could have been involved in reading without a contribution from the secondary visual system.

\subsection{The Larger Context of the Subcortical Pathway}

There is need to contextualize the subcortical visual pathway in humans. Let us proceed by first describing the cortical visual pathway. As with other primates, the main route in humans has the lateral geniculate nucleus as its thalamic relay. The primary target of the geniculate pathway is V1. For a long time, the cortical visual route was rendered as the only visual route that is active in humans [25].

Indeed, in their vast majority, the retinal ganglions of the primates are directed to the lateral geniculate nucleus. Only a small fraction of them projects unto the superior colliculus. Thence, it continues to the pulvinar nuclei. The great majority of that fraction of ganglions is targeting the inferior nuclei. We know that the inferior pulvinar has zero connections with the amygdala [6]. There is a generous number of pulvinar-amygdala connections, indeed, but only a very small fraction of these continues from the superior colliculus [18]. Thus, only in very fortunate scenarios, the activity of the superior colliculus, taken together with that of the pulvinar, will include activity from the dorsal or dorso-median pulvinar. In such a case, the odds of involving the subcortical pathway appear to be low.

If we were to limit ourselves to a comparison between the activity patterns observed in reading by Skeide et al. [1] and what is required to infer the activity of the subcortical passage, chances that this pathway is participating in reading look slim by now. Nevertheless, a key element turns this situation on its head. As we will see, those geometric patterns counting as an important trigger in snake detection correspond strongly and specifically to features pertaining to different types of writing.

\section{Snake Detection Theory and Graphic Characters}

\subsection{Angles and Diamonds}

The preference for angular representations and chevron or herringbone patterns 
is one of the specialties of the V2 area [26] [27]. The size of the angular formations is considered to be largely unimportant. Furthermore, it was reported that many of the V2 cells impacted by angles do not react to the continuous lines that create the angular patterns. Also, it seems that many V2 neurons that react to compositions of multiple lines fail to react towards separated lines [26]. Isbell noted that in V2, some cells tend to react to corners, shape occlusions, and very short segments. Another feature which she mentions is that the area has a preference for elongated objects in movement. Isbell also links the proclivity for (shape) occlusions, which call for depth perception, with the attribute of binocular responsivity. Binocular responsivity is greatly indebted to the V2 area. It is a property unlikely to be found among V1 cells, for instance. Isbell conjectured that V2 has much to do with the fine visual alignment of short segments required for an almost perfect three-dimensional perspective [4]. An expertise in shapes is the gist of the discussion about V2. But not the empirical shapes are at issue here. Also, it isn't about all types of imaginary shapes. We should speak rather of logical shapes. The interpolation (deduction) or the extrapolation (induction) of lines, even when working with very fragmented initial segments, is exhibited by V2 as one of its chief functions. Such abilities are to be found in about one third of V2 neurons [28]. That is a vocation hard to find among V1 cells, even though the properties of those V2 cells are based on properties of the V1 cells [29] [30].

Isbell, when working on the original version of SDT, already noted that some V4 cells react to chessboard patterns. She also says that V4 is chromatically sensitive [4]. These considerations may require a few additions. On the issue of shapes, neurons from the area distributes positions to the objects perceived based on the proportions of their outline. It is ensuring the consistency of size. In addition, there is a rather pronounced sensitivity to where exactly a fragment of a shape is (to be) positioned. Moreover, there is a preference, at the level of the same area, for concentric and radial patterns [31]. Such size consistency-related properties are here in charge with relative depth. There are also other depth-related types of signaling emerging from responses to overlapping and occluding surfaces. While area $\mathrm{V} 4$ has even more refined properties concerning the depth perception than area V2, we should clarify what can be understood by this: the processing of a single edge contour depends on the context of other (neighbor) edge contours. Also, it is not really clear what is the role played by V4 in color perception [32]. Considering color too, the area is preoccupied with constancy. It should be mentioned that V4 has a special responsivity towards colored boundaries [31] [32]. When considering this visual area, one shall speak of a specialization in very complex shapes, a specialization in empirical shapes, as opposed to logical ones, or: a skill for finer analogies and disanalogies. When lesions of the V4 were present in macaques, that increased the level of contrast needed to distinguish between shapes. The problem grew when it came to discriminate between shapes that are extremely complex [33]. 
Those V2 and, to a certain degree, V4 qualities we focus on suit well to a situation of partial exposure of a snake, i.e. camouflage pattern of the snake being occluded by vegetation. Many species of snakes are actually lurking in vegetation. At least, that is suggested by the widespread presence of the vertically elongated pupil in snakes [34]. Such pupils found in ambush predators are used to create an astigmatic depth of field. Vertical contours-such as those of a dog, but even more, of a human-appear sharp even if they are very near or very far from where the forager has its focal point [35]. And, on the other hand, the patterns of the snake scales elicit a stronger early posterior negativity (EPN) than those of the scales of lizards, or of bird feathers, etc. They also surpass such patterns when exposure is partial [27] [36]. EPN reflects visual processing of emotionally significant visual stimuli, or, otherwise said, it represents selection of visual stimuli for further processing, being associated with the basic motivational systems of approach and avoidance. e.g., erotic or violent pictures elicit a strong EPN [37]. Also, other venomous creatures seem weaker than snakes at gaining our evolutionary motivated attention [38]. Triangular/diamond-shaped snake skin patterns elicit a more pronounced EPN than the snake skin which has no patterns. In fact, as opposed to the skin of a diamond-patterned snake, a snake skin which is not patterned is perceived as no more dangerous than the skin of a frog, if only a patch of skin is available to the viewer [37]. It was asserted that the EPN might be always analogous not to an unconscious or preconscious activity, but to a degree of consciousness [27] [39] [40]. On attributes like conscious vs. un-/pre-conscious in this case we will comment later on.

Writing can, be (poli)angular and multilinear, and very complex in a formal sense, which is something substantially different. This affirmation can be easily explained starting from by an excellent point made by Skeide et al.-yet, the same point may have been made in any review of neural activity during reading. This, provided that the review looked into correlations between the aesthetic complexity in various writing system and the fMRI activity patterns reported so far for reading (in different writing systems). What did Skeide et al. note on this subject? On one hand, that the typical alphabetic scripts tend to activate only V1 and V2. On the other hand, that signs with greater aesthetical complexity, whether we are speaking of the Devanāgarī characters, pertaining to an alphasyllabary, or of the Chinese ideograms, will activate V3 and V4 together with V1 and V2 [1]. Yet, without a strong link between the "predilection" for detecting snakes and the patterns that usually pertain to the skin of dangerous snakes, our general hypothesis would be shaky.

Fortunately, the required relationship is clearly encouraged by experimental results [27] [36] [41] [42]. Moreover, snakes with patterns like irregular transverse stripes, as opposed to longitudinally striped snakes and to blotched ones, show a powerful correlation with aggressive responses, often venomous [43]. More so, in contrast to the skin patterns, the curvilinear shape of the body [44], or chromatics are of little importance in rapid snake spotting; on the issue of 
color, there seems to be an exception for snake detection in (small, at least under 10 years) children, which, nonetheless, if extant here in such a mixed form (patterns plus chromatics), occurs slower [45] [46]. It is certain that small children perceive triangular shapes as dangerous. This might to be the reason for the fear of snakes, particularly of venomous snakes, observed in various animals [47].

Apparently, many animals had developed a danger detection system triggered by triangular shapes, represented naturally by fangs, claws, or spikes. Some snakes, typically venomous snakes, started to exploit, seemingly as much as they could, this adaptation pertaining to other animals. These venomous snakes fashioned themselves spear-like heads and zig-zag dorsal patterns [47]. A study using Plasticine models imitating adders/snakes with adder patterns, as opposed to plain snake models, had revealed that snake models are less frequently attacked from the air. Avoidance of the adder models was even stronger when they were placed on a plain background. The reason behind was thus not being incapable to locate the adders because the zig-zag band had provided crypsis to its wearers. The avian predators were actively avoiding models with an adder pattern [48]. The mentioned observation is convergent with data revealing that snakes that score as the most feared ones come from the Viperidae (Crotalinae, Viperinae, and Azemiopinae) family [49].

So, let us highlight the more plausible conclusion to be derived with regard to the macroevolutionary scope of the SDT. Compared with the original scenario advanced by the SDT, this conclusion runs in the opposite direction, being sort of an "evil" twin. It is not (so much) the visual system in primates that evolved to detect dangerous snakes, it says. Rather, the venomous snake had evolved more towards scaring his neighbors, based on their perceptual features. This version is more consistent with the observation that the three main structures that constitute the subcortical visual route contain multiple phylogenetic fingerprints [50]. It also explains, at least partially, why Wheeler, Bradley \& Kamilar could not find any relationship between orbital convergence in primates and shared evolutionary history with venomous snakes, quite the opposite [2].

We should not omit the pulvinar neurons reported to react preferentially to diamond or checkerboard patterns [51] Also, neurons from the superior colliculus seem to respond preferentially to "flickering" chessboard patterns, either moving or stationary [52]. Yet, also, to limit the properties of the subcortical neurons involved in snake detection to the ones mentioned would not be cautious. Some cells in the pulvinar were reported as sensitive to snake postures, as they appear to discriminate the ready-to-attack stances from the not-as-threatening ones [6]. All in all, when patterns resembling a(n occluded) venomous snake are the main features of an image, and a contribution from the areas V2 and V4 is noticed, as is the case in reading, the assumption of a complementary participation starts to gain some plausibility. As we will see in unit 3.3, this plausibility is further cemented. 


\subsection{A Comparative Glance at "Affective Blindsight"}

A glance upon the phenomenon of "affective blindsight" is called for. In the case of "affective blindsight", we are dealing with a class of visual perceptions for which the subcortical route is the main suspect [25] [53] [54] [55] [56] [57]. "Affective blindsight" usually means an accurate visual perception of (some) facial expressions by clinically blind patients. In general, studies of this phenomenon make use of images of fearful faces [25] [55]. Expressions that are socially relevant, denoting thrust, competence, friendliness, etc., yet neutral from the emotional point of view, were also found to be detectable via "affective blindsight" [53]. The "affective blindsight" can also be found in perfectly non-blind subjects, in fact. This, of course, only under certain conditions, as short exposure time [58], or obscurity [59].

Jolij had proposed the following model to make sense of past observations: subcortical processing of (emotional) faces (/stimuli that are relevant for the subcortical pathway) takes place also in non-blind persons, yet the non-blind subject can't identify the expression of a face via the subcortical passage because of repression coming from the part of cortical computation [60]. However, Ajina, Pollard \& Bridge found that the clinically blind persons they had investigated had good detection, yet rather no discrimination skills [53]. This is in agreement with the hypothesis defended by Wang and his colleagues: the subcortical pathway itself does not detect the location or the identity of the object, but its task is to alert the brain that something important happens (or ceases to happen) [61].

The approach we want to introduce here is the functional approach regarding "affective blindsight". Its foundational question is: what if "affective blindsight" is not based on critical physical characteristics? According to the functional approach, the "affective blindsight" implies a functional analysis of the image. Such a description gives a better explanation for the way the cerebral structures contributing to "affective blindsight" operate [62]. On the other hand, it seems hard to believe physical features are to be washed away completely. E.g., considering the presence of the shape of the letter " $v$ " between the eyebrows of a face, it deserves to be added that, this sharp angular shape, when pointing downwards, has its place in evaluating other stimuli as threats [63] and will be perceived as unpleasant as an abstract sign too [64].

As Ajina, Pollard \& Bridge [53] infirm Cecere, Bertini \& Làdavas [55], visual perception mediated by a subcortical road should be extend from cues for fearful or angry faces towards a rather whole range of cues. Burra et al. [54] found that, as opposed to other types of blindsight, "affective blindsight", which seems to rely exclusively on the subcortical route, is sensitive only to low spatial frequencies, agreeing thus with a more functional (rather than based on physical properties) approach of the "affective blindsight" and going against McFadyen and the team [18]. While high spatial frequencies are associated more with physical properties, low spatial frequencies correspond better to holistic, functional analyses of the stimuli [65]. Low spatial frequencies play a very important role in 
emotional face processing. High spatial frequencies are more important for non-emotional face processing [66]. The conclusion of Burra et al. [54] should be understood as having its own limits-whether we can precisely indicate their action, or only attest their existence. E.g., unlike adults, children, until 8 years at least-an age when they usually have learnt to read already-will process emotional expressions based on high spatial frequencies [66].

\subsection{On the Difference in Response}

We would say that perhaps we are still overlooking something important: a difference arises between the patterns triggering the subcortical pathway and those patterns triggering the activity of V2 and V4, respectively. The subcortical visual patterns conform to a complete exposure of the snake. The cortical ones suit more to partial exposure conditions. At least, this is the case with the V2 patterns. Thus, we take the features of the V2 area as a standard against which our reasoning should be measured. Can we identifiy the visual patterns prompting the recruitment of the pulvinar and the superior colliculus with some more or less intersected lines on a page? If so, what impels us to do it?

Our answer is a resounding yes. There, on the page, is a logical presence of a snake, as neurons of a V2 type can both deduce and induce by linear interpolatios and extrapolations. Compared with the cortico-cortical ones, the pulvinocortical connections may be more relevant for the topographic organization of V2 [67]. The data gathered so far suggests that neurons in each subdivision of the pulvinar have identical properties to those in the cortical areas with which the subdivision is anatomically linked [68].

Thus, as the ventral pulvinar is known to strongly communicate with the early and extrastriate visual areas [22], it is likely that neurons from the ventral pulvinar, with the ventral parts of the lateral pulvinar included here [68], correspond in preferences to the neurons from the visual cortices with whom they connect. Thus, we can rightfully suspect that the participating in reading of the lateral pulvinar [1] includes the ventral subdivision of this region. As we will see, if both subdivisions-dorsal and ventral-of the lateral pulvinar are to participate in reading, there might be a quite autonomous subcortical quality of the processing of reading, taking place in the dorsal subdivision, and an aspect receiving more adjustment from the cortical processing, based in the ventral subdivision.

\section{A Hard to be Matched Influence}

\subsection{The Maps of the Pulvinar. The Out-of-Network-Ness of at Least One Pulvinar Map and the Severe Segregation of the Subcortical Visual Route}

In each brain hemisphere, in the lateral half of the ventral pulvinar, there is a map of half of the visual field. In the right brain, the map region penetrates few millimeters in the ventral portion of the median pulvinar. These maps we refer to now resemble other maps present at the cortical level. All these maps pre- 
sumably form a network. Inside the network, the data might be compared. Aside from these two pulvinar maps, another two have been observed. One is located in the ventral subdivision of the median pulvinar. The other one is to be found in the dorsal subdivision of the lateral pulvinar. They are differently organized from the first maps, and they are thought to stay outside the theorized network [69]. Two subdivisions of the dorso-median pulvinar were recently observed to be particularly responsive to snake images. These subdivisions correspond to the two exceptional maps previously mentioned. These regions that show a particular responsivity to snake stimuli are the ventro-medial part of the median pulvinar and the dorsal region of the lateral pulvinar [24]. Theoretically, both snake clusters are thus inside the dorso-median pulvinar, yet we should pay attention again and again to the fact that brain connectivity is not sharply delineated, involving degrees of connectivity between neighbor divisions [70]. As such, the proximity between the right ventral map extending in the ventral portion of the median pulvinar, and the (right) "snake map" from the ventro-median median pulvinar constitutes a complex issue. However, the snake map found in the dorsal part of the lateral pulvinar seem to be quite isolated from "the maps' network".

If there is a cluster of neurons involved in reading that is part of the ventral subdivision of the lateral pulvinar, the cluster in question may partially overlap in the right brain with the extension of the right ventral map. Nonetheless, Skeide and his colleagues had observed a bilateral activity in the pulvinar of the illiterates during reading. The activation of the pulvinar in reading can't be reduced, thus, to the supposition of an activation of a non-autonomous region of pulvinar. As we saw in the unit 2.1, the dorsal region of the lateral pulvinar is involved more in attentional control and selecting relevant stimuli. As such, the subcortical pathway would be preoccupied primarily not with locating and identifying stimuli, but with alertness.

A diffusion tensor imaging study mentions that all the fibers binding the superior colliculus with the pulvinar, and not continuing towards the amygdala, as well as those binding the pulvinar and the amygdala, and not being continued from the superior coliculus, continue from/to cortical areas. Yet, those bundles of fibers connecting the superior colliculus and the amygdala via the pulvinar and forming the subcortical route are not following this principle. The subcortical pathway finds itself in what can be called a radical anatomical and functional isolation. Even more interestingly, perhaps, in the same study, the region of the pulvinar traversed by the subcortical road is identified with the inferolateral pulvinar [71]. It might be that the subcortical pathway passes through both of the "snake maps".

It is veridical, therefore, that if attention is solicited towards a potentially signifier of danger, this cannot be corrected by cortical operations. Indeed, a situation like reading might acquire initially a "seemingly dangerous" status, because of its shape resemblance with occluded snake patterns, and it might retain it later if a part of the dorso-median pulvinar, thus possessing its attentional profile, 
will dictate that attention should be payed to the graphical patterns even after cortical computation would have learnt to make the difference (much) better. As (a virtually infinite) usefulness in communication for graphical patterns (who should be red with some attention) might be discovered in this way, the conflation with a potentially deadly danger is to be perpetuated, while we can presume that the cortical computation, learning to differentiate better the contexts, reduces as much as it can the intensity with which other parts of the brain accept the dictates of a hyper-alert dorsal region of the lateral pulvinar. Our supposition concords with the resistance to extinction exhibited by evolutionary threats, as opposed to other danger-related stimuli (guns, broken electronics that suggest a short, etc.) [27].

If the pulvinar nuclei are typically bound to functions not higher than assistance of the cortical areas in the decisional process, the dorso-median pulvinar holds decision-making attributions. The firing rate of its neurons was found to express confidence to pursue an action [21]. It may prove relevant that in the left pulvinar a region was reported to be associated with novelty seeking behavior, i.e. sensitivity to reward and impulsiveness [72].

To put these into context, the pulvinar nuclei of the thalamus are a very important center of attention resources management. The emotional relevance of the stimulus adds "points" that determine the amount of attention resources that will be gained by an object, different parts of the pulvinar presumably mediating between several (cortical) networks with an attentional profile [73]. Though we assign an important teleological modulation role to the amygdala, as it will be seen immediately, we would like to warn that the activity of amygdala in the processing of salient stimuli might be dependent on that of the pulvinar [74] [75].

We propose as such that there is a contribution from both snake clusters in reading. The processing of reading would thus be partly independent from the control exercised by a larger network of retinotopic maps, and from direct cortical control altogether, in fact. It should be remarked that this hypothesis is based on the way the graphic characters appear to us, on the properties of the areas involved in the discussion on SDT-especially on the studies on the subcortical pathway-, and on the type of task that reading is-especially in its initial phases, yet not only in this context.

Thus, the results presented by Skeide et al. [1] do not contribute to the edifice of the proposed hypothesis. It is still possible that the activity reported in their study has nothing to do with the subcortical pathway, in fact. On theoretical grounds, our hypothesis is autonomous from that of Skeide et al. [1]. This autonomy should also better secure our claims against (serious) criticism aimed at fMRI studies [76] [77]. Yet we do not think that the observations made by Skeide and his colleagues [1] are hard to reproduce or lack significance. We rather believe that the exceptional character of their observation is due to their study being conducted on illiterate persons. The subcortical reactions of these subjects 
were not yet diminished by reaching an advanced status in reading, we would say.

And, to render unto Caesar his things, we should admit we are extremely grateful for the Skeide et al. paper [1]. There is no doubt, it makes it easier to frame our hypothesis as more than consistent with some minimal, almost granted conclusions from the field of neurobiology, including the fMRI studies. Skeide et al. [1] is, in fact, inspiring us all to raise doubts to the view that reading is exclusively a job for cortical activity. Here, our hypothesis adds "perhaps the opposite is closer to the truth". It is a complete reversal-in the way we see the data fitting together-, the subcortical above the cortical, in terms of importance for the acquisition, perpetuation, and, last but not least, attentional decline of our reading habits, that which our study brings new.

\subsection{Is There A Purely Aesthetic Task for Amygdala in Reading?}

If we endorse subcortical pathway recruitment, it means the contribution of the amygdala in reading, not detected in the study of Skeide et al. [1], is implied. We begin by saying that it is fairly reasonable to have no such record. Let us start from the gap between reading and watching a snake. Owing to an act of perceptual conflation, there would be strong reasons for the subcortical passage to activate here. Yet there would be also reasons to drastically diminish its activity, which may result in non-detection from the part of the imagistic technique involved so far: such is the case because, after initial stronger associations, the whole biological system involved, should have learnt a comforting lesson: possibly deadly patterns, so often, are not (so) deadly. But the potential size of the hazard, perhaps lethal in the event of an error, suggests that the guard cannot be lowered completely: the response reduces its power adaptatively, yet it may not disappear so easily, taking into view that, in the case with which we are here concerned, the price for the avoidance a potential death (the attack of a venomous snake) is only a spark of panic. Moreover, this would be the ecological reason for the neurobiological situation (the residual character doubled by an anatomical and functional segregation of the subcortical visual pathway) exposed previously.

Decades ago, a strong association between the subcortical visual pathway and the right amygdala was reported [78]. But, according to more recent studies, the activity involving the superior colliculus, the pulvinar and the amygdala in the context of the occurrence of a threat is balanced between both hemispheres. We surely need to introduce some distinctions here. Let us proceed from the fact that a much weaker activation of the secondary visual system is induced by the presence of fake snakes-compared to the one induced by real ones. However, fake snake representations induce activation. (They even do it more energetically than real snake heads.) Nonetheless in the case of fake snakes, the bilateral reaction of the amygdala is inversely balanced. The real snakes impact the left amygdala more strongly. But fake snakes-which might bear a closer resemblance to 
graphical stimuli-induce a stronger right lateralization [50]. Perhaps the bilateral activation of the amygdala stands for an interhemispheric information transfer [79].

It seems there is a preference in the left section for images that evoke reasons for fear, as scared faces are surely bound to [80] [81]. Also, the left amygdala, as opposed to the right one, seem to be, according to a lesion study, important for the emotional enhancement of some stimuli, including aversive ones [81].

Some regions of the right amygdala may have a broader function [82]. It may be that the less frequently found activation of the right amygdala in studies and meta-analyses owes to the fact that the right amygdala is involved in the initial and fast detection of stimuli. As such, the right nucleus processes data in a shorter time [83]. Reports of a broader function of the right nucleus of the amygdala are opposed by others, e.g., stimulation of the right amygdala was found to be accompanied only by negative emotional responses. In fact, it was the stimulation of the left amygdala that elicited both positive and negative responses [84]. It may be deemed certain that fear, together with initiation of defensive mechanisms cannot be excluded from the attributions of the right amygdala. More so, the right, and not the left side of the basolateral amygdala is presumed to initiate defensive responses via the subcortical pathway [85].

It may prove useful to look into the different properties of the basolateral and centromedial amygdala. The hypothesis of bilateral activation standing for an interhemispheric information transfer may be found later to be in (dis)agreement with the properties of the basolateral and the centromedial [86], if we take the transition from left to right to be one from the basolateral to the centromedial, as we are encouraged to do by McFadyen, Mattingley \& Garrido [87]. The fact that we seem to already know that rewarding stimuli (water, sucrose) primarily activate the posterior basolateral amygdala, and aversive stimuli (trimethylthiazoline, quinine) primarily activate the anterior basolateral amygdala [88] may be of some utility in future research on this subcortical issue. The basolateral amygdala, known for its role in processing faces and threats, seems to be the target of the subcortical pathway. Yet, we are far from having a clear picture of the problem. As such, we can't say if only the anterior, or only the posterior basolateral amygdala is involved. It is possible that both anterior and posterior basolateral amygdala are constantly active when we read-although under the technical threshold of typical fMRI possibilities.

We should remark that, the majority of the fibers going from the pulvinar to the amygdala runs to the basolateral division in the left hemisphere. The situation is reversed in regard with the right amygdala. The centromedial division is here the one predominantly targeted [87]. It does not mean there no fibers connect the pulvinar and the right basolateral amygdala, our main suspect. When noticing the aversive stimuli, the basolateral nucleus is capable to adjust towards the real threat level. The centromedial nucleus, while responding to aversive outcomes, is insensitive to aversive cues and associated expectations [86]. Con- 
clusions derived by observing several types of lesions of the amygdala encourage us to see both its central and its basolateral nuclei as engaged in the processing of both types of stimuli, aversive and appetitive. We must also emphasize that the basolateral and central amygdala are strongly interconnected [89].

Data provided by Almeida, Soares \& Castelo-Branco regarding the preservation of a bilateral, though inversed reaction [50] favors now, looking to the highlighted correspondences between snake detection and reading, the idea that, in reading too, fear triggering and amygdala activation can't truly disappear. Examining the issue, it may prove plausible that the activity of the amygdala in reading is weaker than the current technical possibilities for detection-or maybe not, and the amygdala is not activated. What other possibilities may lie there? Certainly, lots of them, in the current stage of neurosciences.

\subsection{On Consciousness, and the Consequences of an Anatomical Isolation of the Subcortical Pathway}

If the subcortical road is not under direct cortical control, it seems that it is immaterial whether the information is processed at a relatively low speed, or not. If there is some inaccuracy intrinsic to the information mediated by the extra-geniculate route, its status does not depend on its speed of transfer. As such, it is irrelevant if the transfer speed corresponds to conscious computation. Indeed, the usual unconscious visual perception observed in clinically blind subjects, "type 1 blindsight" (as opposed to "affective blindsight", or "type 2 blindsight") [90] is due to the neuroplastic reinforcement of some fibers that bypass V1. In the case of healthy subjects, unconscious visual perceptions seem to be mediated by the geniculate pathway. The geniculate pathway is perfectly suited for rapid processing [29] [91] [92] [93] [94].

But there is a catch here. Because of the anatomical and functional isolation of the route, an extra-geniculate mediated perception should be untouched or at least, unaffected by consciousness. In the special case of reading, after a while, this "affective blindsight" seems to stay entirely untouchable. The response, while extremely frequent, becomes very quickly a much too subtle one, according to our hypothesis. Also, perceiving some strange sensations while reading becomes impossible for the reacting humans that are quite rapidly "saturated" with script (and similar artificial patterns).

The very thought that emotionally charged processing requires awareness [3] is to be translated, in the context of the subcortical pathway, as such: unconscious emotional responses require pre-oriented attention towards the stimulus. When we enter a focused disposition, this may equal an anticipatory disposition. Here we agree with Kawai [27], who is remarking that there must be "preparedness" in order to fear the snake. It is enough, we think, to still find something-a second use for them-interesting in those danger patterns that we can easily reproduce on a solid material. The preparation would elicit an unconscious danger reaction if the stimuli upon which we have focused-a process which seems to be (partly) unconscious-correspond at least in part with the danger pattern. 
According to Kawai, because the cortical activity occurs before the activation of the subcortical pathway, snake detection should not be regarded as unconscious [27]. As already seen, we disagree with the way he is reasoning here, and thus with his sharp conclusion. On the other hand, an interesting model involving continuous degrees of consciousness was proposed by some researchers [95] [96] [97]. However, we should stress that not consciousness per se interests us in relation with the activity of the subcortical visual passage. What is most important here, according to us, is that the subcortical visual pathway in humans possesses a functional autonomy not extinguishable through cortical computation, and, on the other hand, this autonomous system has the leverage to influence decisively the course of our actions.

\subsection{Where Is It Leading?}

What direction will this subcortical influence of script take? We will introduce first the "delayed detachment" hypothesis. According to it, objects signifying imminent danger capture our attention easier than those that don't, and also seize it for a longer time. Experimental observations cement the high importance of gazing at a potentially dangerous stimulus. It seems so, in order to compute the size of that danger [98]. Snakes, it should be said, draw attention as fast as an angry face, but they capture it for a longer time [99]. Given the importance of the amygdala in this discussion, and its dual, aversive-appetitive nature, the longterm output of recruiting the retino-tectal pathway with regard to writing could be a self-reinforcing addictive behavior. This behavior would have begun with the suspicion of a potential danger coming from the stimuli, repeatedly "denied" by outcomes, but never absolutely.

The amygdala does not comprise only (a part of the) fear processing: it iseven much more, seemingly-involved in the performance of appetitive tasks, too. These are tasks performed for a certain reward. The reward can be attached to Pavlovian motivational stimuli. Those are neutral in the beginning, but they are in position to become conditioned stimuli of attraction. Emotional representation of conditioned stimuli is important. Some conditioned stimuli are more potent than others, e.g. light is more powerful, being a more precise indicator than sound. The amygdala does not act on its own in such cases, in fact, but it interacts with a large cortico-striatal circuit [89] [100]. It was recently shown that the basolateral amygdala can be associated not only with coupling conditioned stimuli and rewards, but also with facilitating instrumental pursuit of the conditioned stimuli, favoring maladaptive behaviors [101].

We recall that it seems impossible to eliminate the aversive element from the graphic stimulus, that the response should become less and less intense, and that it is presumable that the aversive element may be (partially) turned into an appetitive one. As such, light may act as a conditioned stimulus for attraction which is more and more intense, in order to compensate for the loss in intensity by the unconditional stimulus. The interest towards script should thus come finally as 
ornamental, compared with the one towards the luminous medium.

If we were to extrapolate this scheme to the scale of society, what output is to be derived? It is reasonable to infer that actions taken by numerous individuals reacting and being strongly motivated in the same vein, without being planned as such, have a spontaneous tendency to converge. Once there is further development towards a specific direction, and a path starts to having been partially cleared, major planning starts to happen as well. Given our circumstances, this appears to be the stirring factor for a civilization to increase the use of light in association with reading and finally that of various light-writing interlaces, e.g., the luminous display. Another presumable output: society will speed up its pace, generally promoting light qualities as transparency and detachment, by way of denouncing secrecy and resistance towards change and secrecy.

We should emphasize that, taken the way it is, the proposed hypothesis can't support measures against adverse effects of artificial light [102] [103] [104], or of some specific wavelengths prominent in some of the artificial light, as blue light stands [103] [105] [106] [107]. Far from it. Suppose that we remove, as much as possible, the unwanted sources of light, yet we also preserve some outputs of this powerful fascination with light concerning photobiomodulation that are envisaged as truly desirable [108] [109]. Is this selection relevant? No. The cause remains active. The cause remains hidden. The cause preserves the same direction. Even if achievable-and presumably, achievable only if such measures appear at a time as necessary for the survival of the teleology of the system-, measures against some aspects of the addiction would not produce a deviation from its course. Through greater efforts to conform to its never to be touched ideal, the social system described, one never of light for itself, but always of the stronger refusal of darkness and its associates, e.g., likeliness of lethal dangers, is, in fact, liable to produce its own destruction. This is because of an unavoidable growth of intolerance towards any alternative that could be really an alternative to it, and thus against its neutrality, openness, tolerance towards alternatives, etc. At least, that's what we will find if we study the features of the system in a linear, logical manner, which, on the other hand, it's unlikely that will ever be fully credited by us, humans. Indeed, considering that we deal here with a bias deeply rooted in the optative-decisional process, a cataclysmic outcome appears to slide onto the edge of near solid certitude.

\section{Conclusions}

A minimalistic alphabetic script is different from other scripts by not activating the V4 area, and as such, the deduced V4 type neurons within the subcortical visual route will also be disengaged from reading by these alphabets. To be taken with a pinch of salt, the alphabetical human rather lacks something. Nowadays, we do know that the subcortical activity is having a great impact upon the general way of our thinking. We can take here the example of the pulvinar anesthesia, which has profound consequences on cortical activity [68]. Bearing in mind 
such an example, we are of the opinion that we have to find/build a framework that helps the hypothesis presented here to reach its theoretical potential. For now, that would be a job for the active inference theory. According to this vision, imparting attention to a target area follows our desire to attain a clearer view on the causes of our more disturbing sensations [110] [111]. Hence, a link between what draws and captures our visual interest and the way we process information much more generally is to be suspected.

If greater training of the $\mathrm{V} 2$ leads to better three-dimensional representation, this linearization of space should also have a cognitive impact that is specific. We reason that a penchant for constancy and preservation of given structures is more likely to be found in societies that do not share preeminently a graphical minimalism. The inclination of V4 towards radial and concentric patterns suggests hierarchical and cyclical models of reality. Therefore, we propose the existence of a neurobiological "rift". Depending on which side of it we stand, this "neuro-rift" supports/disfavors,-if not almost precludes-the emergence of the "Western" cultural consequences, e.g., of the three-dimensional pictorial representation and of the "rational" science. The aesthetic simplification of writing might be correlated (also) with less awe for the graphic characters. Perhaps many are at least tending to see, if not downright seeing such a trend when looking at global history.

Indeed, historically, the graphically minimalistic alphabets might seem, at a first glance, to generally suit to a more secularized/less magical status of writing, and also, to a greater praising of light/lesser validation for darkness, and also snakes, dragons, etc. But the trend may behave as such not because of the aesthetic reduction operated. It seems to us more likely that, in the case of these minimalistic scripts, their cognitive features-their user-friendly phonetic character-will encourage a larger, more frequent and thus more intensity diminishing use. Nonetheless, in the very first stages, the minimalistic signs might, by themselves, elicit (much) stronger reactions than aesthetically complex scriptsa camouflaged snake is more likely to kill me than a non-camouflaged one [40] [112].

Our hypothesis may strike you as raising too powerful doubts related to the way we live. It revels the cause(s) of a plausible end for many. If we want to prevent such an end, should we not think of surgically altering the retino-tectal route? It seems so. But, will we stop there? In a stage of addiction, in which light is highly important, as the current one should be for many of us, we may also need to alter the large cortico-striatal circuit, the one which, together with the amygdala, is involved in the emotional representation of the conditioned stimuli. Can we stop there? Should we try? These are questions that may help us to underscore a simple truth: how absurd it is to try to overcome an addiction like the one outlined, if we are not detaining a proper strategy! In fact, following the hypothesis, in spite of our most scrupulous ratiocination, our addicted attitude pushes the problem further. To stand a chance, we have to address the cause(s) 
as indirectly as possible. "Indirectness" refers here to the non-linearity of the thinking behind any presumably efficient approach of the designated problem. Yet, otherwise put, to system(at)ically prioritize the use of a more developed technology because of its recent status seems to be the most indirect approachin the sense of a never-touching the root(s) of the problem one.

\section{Conflicts of Interest}

The author declares no conflicts of interest regarding the publication of this paper.

\section{References}

[1] Skeide, M.A., Kumar, U., Mishra, R.K., Tripathi, V.N., Guleria, A., Singh, J.P., Eisner, F. and Huettig, F. (2017) Learning to Read Alters Cortico-Subcortical Cross-Talk in the Visual System of Illiterates. Science Advances, 3, e1602612. https://doi.org/10.1126/sciadv.1602612

[2] Wheeler, B.C., Bradley, B.J. and Kamilar, J.M. (2011) Predictor of Orbital Convergence in Primates: A Test of the Snake Detection Hypothesis of Primate Evolution. Journal of Human Evolution, 61, 233-242. https://doi.org/10.1016/j.jhevol.2011.03.007

[3] Coelho, C.M., Suttiwan, P., Faiz, A.M., Ferreira-Santos, F. and Zsido, A.N. (2019) Are Humans Prepared to Detect, Fear, and Avoid Snakes? The Mismatch between Laboratory and Ecological Evidence. Frontiers in Psychology, 10, Article No. 2094. https://doi.org/10.3389/fpsyg.2019.02094

[4] Isbell, L.A. (2009) The Fruit, the Three, and the Serpent: Why We See So Well? Harvard University Press, Cambridge \& London. https://doi.org/10.2307/j.ctvjnrvj0

[5] Shimizu, T., Patton, T.B., Szafranski, G. and Butler, A.B. (2009) Evolution of the Visual System in Reptiles and Birds. In: Binder, M.D., Hirokawa, N. and Windhorst, U., Eds., Encyclopedia of Neuroscience, Springer, Berlin \& Heidelberg, 1466-1472. https://doi.org/10.1007/978-3-540-29678-2 3179

[6] Carr, J.A. (2015) I'll Take the Low Road: The Evolutionary Underpinnings of Visually Triggered Fear. Frontier in Neuroscience, 9, 414. https://doi.org/10.3389/fnins.2015.00414

[7] Da Silva, F.O., Fabre, A.-C., Savriama, Y., Ollonen, J., Mahlow, K., Herrel, A., Müller, J. and Di-Poï, N. (2018) The Ecological Origins of Snakes as Revealed by Skull Evolution. Nature Communications, 9, Article No. 376. https://doi.org/10.1038/s41467-017-02788-3

[8] Watanabe, A., Fabre, A.-C., Felice, R.N., Maisano, J.A., Müller, J., Herrel, A. and Goswami, A. (2019) Ecomorphological Diversification in Squamates from Conserved Pattern of Cranial Integration. PNAS, 116, 14688-14697. https://doi.org/10.1073/pnas.1820967116

[9] Morinaga, G. and Bergmann, P.J. (2020) Evolution of Fossorial Locomotion in the Transition from Tetrapod to Snake-Like Lizards. Proceedings of Royal Society $B$, 287. https://doi.org/10.1098/rspb.2020.0192

[10] Simões, B.F., Sampaio, F.L., Jared, C., Antoniazzi, M.M., Loew, E.R., Bowmaker, J.K., Rodriguez, A., Hart, N.S., Hunt, D.M., Partridge, J.C. and Gower, D.J. (2015) Visual System Evolution and the Nature of the Ancestral Snake. Journal of Evolutionary Biology, 28, 1309-1320. https://doi.org/10.1111/jeb.12663 
[11] Cyriac, V.P. and Kodandaramaiah, U. (2018) Digging Their Own Macroevolutionary Grave: Fossoriality as an Evolutionary Dead End in Snakes. Journal of Evolutionary Biology, 31, 587-598. https://doi.org/10.1111/jeb.13248

[12] Mahler, D.L., Weber, M.G., Wagner, C.E. and Ingram, T. (2017) Pattern and Process in the Comparative Study of Convergent Evolution. The American Naturalist, 190, S13-S28. https://doi.org/10.1086/692648

[13] Peirce, T. (2012) Convergence and Parallelism in Evolution: A Neo-Gouldian Account. The British Journal for the Philosophy of Science, 63, 429-468. https://doi.org/10.1093/bjps/axr046

[14] Stayton, C.T. (2015) The Definition, Recognition, and Interpretation of Convergent Evolution, and Two New Measures for Quantifying and Assessing the Significance of Convergence. Evolution, 69, 2140-2153. https://doi.org/10.1111/evo.12729

[15] Kinoshita, M., Kato, R., Isa, K., Kobayashi, K., Kobayashi, K., Onoe, H. and Isa, T. (2019) Dissecting the Circuit for Blindsight to Reveal the Critical Role of Pulvinar and Superior Colliculus. Nature Communications, 10, Article No. 135. https://doi.org/10.1038/s41467-018-08058-0

[16] Koller, K., Rafal, R.D., Platt, A. and Mitchell, N.D. (2018) Orienting toward Threat: Contributions of a Subcortical Pathway Transmitting Retinal Afferents to the Amygdala via the Superior Colliculus and Pulvinar. Neuropsychologia, 128, 78-86. https://doi.org/10.1016/j.neuropsychologia.2018.01.027

[17] McFadyen, J. (2019) Investigating the Subcortical Route to the Amygdala across Species and in Disordered Fear Responses. Journal of Experimental Neuroscience, 13. https://doi.org/10.1177/1179069519846445

[18] McFadyen, J., Mermillod, M., Mattingley, J.B., Halász, V. and Garrido, M.I. (2017) A Rapid Subcortical Amygdala Route for Faces Irrespective of Spatial Frequency and Emotion. Journal of Neuroscience, 37, 3864-3874. https://doi.org/10.1523/JNEUROSCI.3525-16.2017

[19] Shipp, S. (2003) The Functional Logic of Cortico-Pulvinar Connections. Philosophical Transactions of the Royal Society B: Biological Sciences, 358, 1605-1624. https://doi.org/10.1098/rstb.2002.1213

[20] Wilke, M., Schneider, L., Dominguez-Vargas, A.-U., Schmidt-Samoa, C., Miloserdov, K., Nazzal, A., Dechent, P., Cabral-Calderin, Y., Scherberger, H., Kagan, I. and Bähr, M. (2018) Reach and Grasp Deficits Following Damage to the Dorsal Pulvinar. Cortex, 99, 135-149. https://doi.org/10.1016/j.cortex.2017.10.011

[21] Fiebelkorn, I.C. and Kastner, S. (2019) The Puzzling Pulvinar. Neuron, 101, 201-203. https://doi.org/10.1016/j.neuron.2018.12.032

[22] Arcaro, M.J., Pinsk, M.A., Chen, J. and Kastner, S. (2018) Organizing Principles of Pulvino-Cortical Functional Coupling in Humans. Nature Communications, 9, Article No. 5382. https://doi.org/10.1038/s41467-018-07725-6

[23] Hakamata, Y., Sato, E., Komi, S., Moriguchi, Y., Izawa, S., Murayama, N., Hanakawa, T., Inoue, Y. and Tagaya, H. (2016) The Functional Activity and Effective Connectivity of Pulvinar are Modulated by Individual Differences in Threat-Related Attentional Bias. Scientific Reports, 6, Article No. 34777. https://doi.org/10.1038/srep34777

[24] Elorette, C., Forcelli, P.A., Saunders, R.C. and Malkova, L. (2018) Colocalization of Tectal Inputs with Amygdala-Projecting Neurons in the Macaque Pulvinar. Frontiers in Neural Circuits, 12, 91. https://doi.org/10.3389/fncir.2018.00091

[25] Tamietto, M. and Morrone, M.C. (2016) Visual Plasticity: Blindsight Bridges Anatomy and Function in the Visual System. Current Biology, 26, 70-73. 
https://doi.org/10.1016/j.cub.2015.11.026

[26] Boynton, G.M. and Hegdé, J. (2004) Visual Cortex: The Continuing Puzzle of Area V2. Current Biology, 14, 523-524. https://doi.org/10.1016/j.cub.2004.06.044

[27] Kawai, N. (2019) The Fear of Snakes. Evolutionary and Psychobiological Perspectives on Our Innate Fear. Springer Nature Singapore Pte Ltd., Singapore. https://doi.org/10.1007/978-981-13-7530-9

[28] Peterhans, E. and von der Heydt, R. (1989) Mechanisms of Contour Perception in Monkey Visual Cortex. II. Contour Bridging Gaps. Journal of Neuroscience, 9, 14491763. https://doi.org/10.1523/JNEUROSCI.09-05-01749.1989

[29] Cohen, A., Buia, C. and Tiesinga, P. (2014) Dependence of V2 Illusory Contour Response on V1 Cell Properties and Topographic Organization. Biological Cybernetics, 108, 337-354. https://doi.org/10.1007/s00422-014-0602-x

[30] Ramsden, B.M., Hung, C.P. and Roe, A.W. (2001) Real and Illusory Contour Processing in Area V1 of the Primate: A Cortical Balancing Act. Cerebral Cortex, 11, 648-665. https://doi.org/10.1093/cercor/11.7.648

[31] Roe, A.W., Chelazzi, L., Connor, C.E., Conway, B.R., Fujita, I., Gallant, J.L., Lu, H. and Vanduffel, W. (2012) Toward a Unified Theory of Visual Area V4. Neuron, 74, 12-29. https://doi.org/10.1016/j.neuron.2012.03.011

[32] Parker, A.J. (2020) Intermediate Level Cortical Areas and the Multiple Roles of Area V4. Current Opinion in Physiology, 16, 61-67. https://doi.org/10.1016/j.cophys.2020.07.003

[33] Merrigan, W.H. and Pham, H.A. (1998) V4 Lesions in Macaques Affect Both Single- and Multiple-Viewpoint Shape Discriminations. Visual Neuroscience, 15, 359 367. https://doi.org/10.1017/S0952523898152112

[34] Brischoux, F., Pizzatto, L. and Shine, R. (2010) Insight into the Adaptive Significance of Vertical Pupil in Snakes. Journal of Evolutionary Biology, 23, 1878-1885. https://doi.org/10.1111/j.1420-9101.2010.02046.x

[35] Banks, M.S., Sprague, W.W., Schmoll, J., Parnell, J.A.Q. and Love, G.D. (2015) Why Do Animal Eyes Have Pupils of Different Shapes? Science Advances, 7, e1500391. https://doi.org/10.1126/sciadv.1500391

[36] van Strien, J.W. and Isbell, L.A. (2017) Snake Scales, Partial Exposure and the Snake Detection Theory: A Human Event-Related Potentials Study. Scientific Reports, 7, Article No. 46331. https://doi.org/10.1038/srep46331

[37] Grassini, S., Valli, K., Souchet, J., Aubret, F., Revonsuo, G.A. and Koivisto, M. (2019) Pattern Matters: Snakes Exhibiting Triangular and Diamond-Shaped Skin Patterns Modulate Electrophysiological Activity in Human Visual Cortex. Neuropsychologia, 131, 62-72. https://doi.org/10.1016/j.neuropsychologia.2019.05.024

[38] van Strien, J.W. and van der Peijl, M.K. (2018) Enhanced Early Processing in Response to Snake and Tryphophobic Stimuli. BMC Psychology, 6, Article No. 21. https://doi.org/10.1186/s40359-018-0235-2

[39] Eklund, R. and Wiens, S. (2018) Visual Awareness Negativity Is an Early Neural Correlate of Awareness: A Preregistered Study with Two Gabor Sizes. Cognitive, Affective \& Behavioral Neuroscience, 18, 176-188. https://doi.org/10.3758/s13415-018-0562-Z

[40] Grassini, S., Holm, S.K., Railo, H. and Koivisto, M. (2016) Who Is Afraid of the Invisible Snake? Subjective Visual Awareness Modulates Posterior Brain Activity for Evolutionarily Threatening Stimuli. Biological Psychology, 121, 53-61. https://doi.org/10.1016/j.biopsycho.2016.10.007 
[41] Isbell, L.A. and Etting, S.F. (2016) Scales Drive Detection, Attention, and Memory of Snakes in Wild Vervet Monkeys (Chlorocebus pygerythrus). Primates, 58, 121 129. https://doi.org/10.1007/s10329-016-0562-y

[42] Kawai, N. and He, H. (2016) Breaking the Snake Camouflage: Humans Detect Snakes More Accurately than Other Animals under Less Discernible Visual Conditions. PLOS ONE, 11, e0164342. https://doi.org/10.1371/journal.pone.0164342

[43] Allen, W.L., Baddeley, R., Scott-Samuel, N.E. and Cuthill, I.C. (2013) The Evolution and Function of Pattern Diversity in Snakes. Behavioral Ecology, 24, 1237-1250. https://doi.org/10.1093/beheco/art058

[44] van Strien, J.W., Christiaans, G., Franken, I.H.A. and Huijding, J. (2016) Curvilinear Shapes and the Snake Detection Hypothesis: An ERP Study. Psychophysiology, 53, 252-257. https://doi.org/10.1111/psyp.12564

[45] Hayakawa, S., Kawai, N. and Masataka, N. (2011) The Influence of Color on Snake Detection in Visual Search in Human Children. Scientific Reports, 1, Article No. 80. https://doi.org/10.1038/srep00080

[46] Prokop, P., Fančovičová, J. and Kučerová, A. (2018) Aposematic Colouration Does Not Explain Fear of Snakes in Humans. Journal of Ethology, 36, 35-41.

https://doi.org/10.1007/s10164-017-0533-9

[47] Souchet, J. and Aubret, F. (2016) Revisiting the Fear of Snakes in Children: The Role of Aposematic Signalling. Scientific Reports, 6, Article No. 37619.

https://doi.org/10.1038/srep37619

[48] Wüster, W., Allum, C.S.E., Bjargardóttir, I.B., Bailey, K.L., Dawson, K.J., Guenioui, J., Lewis, J., McGurk, J., Moore, A.G., Niskanen, M. and Pollard, C.P. (2004) Do Aposematism and Batesian Mimicry Require Bright Colours? A Test, Using European Viper Markings. Proceedings of Royal Society of London B, 271, 2495-2499. https://doi.org/10.1098/rspb.2004.2894

[49] Rádlová, S., Janovcová, M., Sedláčková, K., Polák, J., Nácar, D., Peléšková, Š., Frynta, D. and Landová, E. (2019) Snakes Represent Emotionally Salient Stimuli That May Evoke Both Fear and Disgust. Frontiers in Psychology, 10, Article No. 1085. https://doi.org/10.3389/fpsyg.2019.01085

[50] Almeida, I., Soares, S.C. and Castelo-Branco, M. (2015) The Distinct Role of the Amygdala, Superior Colliculus and Pulvinar in Processing of Central and Peripheral Snakes. PLoS ONE, 10, e0129949. https://doi.org/10.1371/journal.pone.0129949

[51] Villeneuve, M.Y., Kupers, R., Gjedde, A., Ptito, M. and Casanova, C. (2005) Pattern-Motion Selectivity in the Human Pulvinar. NeuroImage, 28, 474-480. https://doi.org/10.1016/j.neuroimage.2005.06.015

[52] Schneider, K.A. and Kastner, S. (2005) Visual Responses of the Human Superior Colliculus: A High Resolution Functional Resonance Imaging Study. Journal of Neurophysiology, 94, 2491-2503. https://doi.org/10.1152/jn.00288.2005

[53] Ajina, S., Pollard, M. and Bridge, H. (2020) The Superior Colliculus and Amygdala Support Evaluation of Face Trait in Blindsight. Frontiers in Neurology, 11, 769. https://doi.org/10.3389/fneur.2020.00769

[54] Burra, N., Hervais-Adelman, A., Celeghin, A., de Gelder, B. and Pegna, A.J. (2019) Affective Blindsight Relies on Low Spatial Frequencies. Neuropsychologia, 128, 44-49. https://doi.org/10.1016/j.neuropsychologia.2017.10.009

[55] Cecere, R., Bertini, C. and Làdavas, E. (2013) Differential Contribution of Cortical and Subcortical Visual Pathways to the Implicit Processing of Emotional Faces: A tDCS Study. Journal of Neuroscience, 22, 6469-6475. https://doi.org/10.1523/JNEUROSCI.3431-12.2013 
[56] Celeghin, A., Bagnis, A., Diano, M., Méndez, C.A., Costa, T. and Tamietto, M. (2019) Functional Neuroanatomy of Blindsight Revealed by Activation Likelihood Estimation Meta-Analysis. Neuropsychologia, 128, 109-118. https://doi.org/10.1016/j.neuropsychologia.2018.06.007

[57] Garrido, M.I. (2012) Brain Connectivity: The Feel of Blindsight. Current Biology, 22, R599-R600. https://doi.org/10.1016/j.cub.2012.06.012

[58] Tamietto, M. and de Gelder, B. (2008) Affective Blindsight in the Intact Brain: Neural Interhemispheric Summation for Unseen Fearful Expressions. Neuropsychologia, 46, 820-828. https://doi.org/10.1016/j.neuropsychologia.2007.11.002

[59] Jolij, J. and Lamme, V.A.F. (2005) Repression of Unconscious Information by Conscious Processing: Evidence from Affective Blindsight Induced by Transcranial Magnetic Stimulation. PNAS, 102, 10747-10751.

https://doi.org/10.1073/pnas.0500834102

[60] Jolij, J. (2008) From Affective Blindsight to Affective Blindness: When Cortical Processing Suppresses Subcortical Information. In: Columbus, F., Ed., Neural Pathways, Nova Science Publishers, New York, 205-208.

[61] Wang, L., Yang, L.-C., Meng, Q.-L. and Ma, Y.-Y. (2018) Superior Colliculus-Pulvinar-Amygdala Subcortical Visual Pathway. Acta Physiologica Sinica, 70, 79-84.

[62] Celeghin, A., de Gelder, B. and Tamietto, M. (2015) From Affective Blindsight to Emotional Consciousness. Conscious Cognition, 36, 414-425.

https://doi.org/10.1016/j.concog.2015.05.007

[63] LoBue, V. and Larson, C.L. (2010) What Makes an Angry Face Look So... Angry? Examining Visual Attention to the Shape of Threat in Children and Adults. Visual Cognition, 18, 1165-1178. https://doi.org/10.1080/13506281003783675

[64] Larson, C.L., Aronoff, J. and Steuer, E.L. (2012) Simple Geometric Shapes Are Implicitly Associated with Affective Value. Motivation and Emotion, 36, 404-413. https://doi.org/10.1007/s11031-011-9249-2

[65] Goffaux, V. (2006) Faces Are "Spatial"-Holistic Face Perception Is Supported by Low Spatial Frequencies. Journal of Experimental Psychology, Human Perception and Performance, 32, 1023-1039. https://doi.org/10.1037/0096-1523.32.4.1023

[66] Jessen, S. and Grossmann, T. (2017) Exploring the Role of Spatial Frequency during Neural Emotion Processing in Human Infants. Frontiers in Human Neuroscience, 11, 486. https://doi.org/10.3389/fnhum.2017.00486

[67] Takahata, T. (2016) What Does Cytochrome Oxidase Histochemistry Represent in the Visual Cortex. Frontiers in Neuroanatomy, 10, 79. https://doi.org/10.3389/fnana.2016.00079

[68] Zhou, H., Schafer, R.J. and Desimone, R. (2016) Pulvinar-Cortex Interactions in Vision and Attention. Neuron, 89, 209-220. https://doi.org/10.1016/j.neuron.2015.11.034

[69] Arcaro, M.J., Pinsk, M.A. and Kastner, S. (2015) The Anatomical and Functional Organization of the Human Visual Pulvinar. The Journal of Neuroscience, 35, 9848-9871. https://doi.org/10.1523/JNEUROSCI.1575-14.2015

[70] Abivardi, A. and Bach, D.R. (2017) Human Amygdala Nuclei with Thalamus and Cortex Subdivision in Vivo. Human Brain Mapping, 38, 3927-3940.

https://doi.org/10.1002/hbm.23639

[71] Tamietto, M., Pullens, P., de Gelder, B., Weiskrantz, L. and Goebel, R. (2012) Subcortical Connections to Human Amygdala and Changes Following Destruction of the Visual Cortex. Current Biology, 22, 1449-1455. 
https://doi.org/10.1016/j.cub.2012.06.006

[72] Stam, D., Huang, Y.-A. and Van den Stock, J. (2018) Gray Matter Volume of a Region in the Thalamic Pulvinar Is Specifically Associated with Novelty Seeking. Frontiers in Psychology, 9, Article No. 203. https://doi.org/10.3389/fpsyg.2018.00203

[73] Barron, D.S., Eickhoff, S.B., Clos, M. and Fox, P.T. (2015) Human Pulvinar Functional Organization and Connectivity. Human Brain Mapping, 36, 2417-2431. https://doi.org/10.1002/hbm.22781

[74] Bertini, C., Pietrelli, M., Braghittoni, D. and Làdavas, E. (2018) Pulvinar Lesions Disrupt Fear-Related Implicit Visual Processing in Hemianopic Patients. Frontiers in Psychology, 9, Article No. 2329. https://doi.org/10.3389/fpsyg.2018.02329

[75] Ward, R., Calder, A.J., Parker, M. and Arend, I. (2007) Emotion Recognition Following Human Pulvinar Damage. Neuropsychologia, 45, 1973-1978. https://doi.org/10.1016/j.neuropsychologia.2006.09.017

[76] Elliott, M.L., Knodt, A.R., Ireland, D., Morris, M.L., Poulton, R., Ramrakha, S., Sison, M.L., Moffitt, T.E. and Caspi, A. (2020) What Is the Test-Retest Reliability of Common Task-fMRI Measure? New Empirical Evidence and a Meta-Analysis. Psychological Science, 31, 792-806. https://doi.org/10.1177/0956797620916786

[77] Poldrack, R. (2017) Neuroscience. The Risks of Reading the Brain. Nature, 451, 156. https://doi.org/10.1038/541156a

[78] Morris, J.S., Öhman, A. and Dolan, R.J. (1999) A Subcortical Pathway to the Right Amygdala Mediating “Unseen” Fear. PNAS, 96, 1680-1685.

https://doi.org/10.1073/pnas.96.4.1680

[79] Siman-Tov, T., Gadoth, N., Papo, D. and Schonberg, T. (2008) Mind Your Left: Spatial Biasa in Subcortical Fear Processing. Journal of Cognitive Neuroscience, 21, 1782 1789. https://doi.org/10.1162/jocn.2009.21120

[80] Hardee, J.E., Thompson, J.C. and Puce, A. (2008) The Left Amygdala Knows Fear: Laterality in the Amygdala Response to Fearful Eyes. Social Cognitive and Affective Neuroscience, 3, 47-54. https://doi.org/10.1093/scan/nsn001

[81] Herrmann, L., Vicheva, P., Kasties, V., Danyeli, L.V., Szycik, G.R., Denzel, D., Fan, Y., Van der Meer, J., Vester, J.C., Eskoetter, H., Schultz, M. and Walter, M. (2020) fMRI Revealed Reduced Amygdala Activation after Nx4 in Mildly to Moderately Stressed Healthy Volunteers in a Randomized, Placebo-Controlled, Cross-Over Trial. Scientific Reports, 10, Article No. 3802. https://doi.org/10.1038/s41598-020-60392-w

[82] Frühholz, S., Hofstetter, C., Cristinzio, C., Saj, A., Seeck, M., Vuilleumier, P. and Grandjean, D. (2015) Asymmetrical Effects of Unilateral Right or Left Amygdala Damage on Auditory Cortical Processing of Vocal Emotions. PNAS, 112, 1583 1588. https://doi.org/10.1073/pnas.1411315112

[83] Bonnet, L., Comte, A., Tatu, L., Millot, J.-L., Moulin, T. and Medeiros de Bustos, E. (2015) The Role of the Amygdala in the Perception of Positive Emotions: An "Intensity Detector”. Frontiers in Behavioral Neuroscience, 9, Article No. 178. https://doi.org/10.3389/fnbeh.2015.00178

[84] Lanteaume, L. Khalfa, S., Régis, J., Marquis, P., Chauvel, P. and Bartolomei, F. (2007) Emotion Induction after Direct Intracerebral Stimulations of Human Amygdala. Cerebral Cortex, 17, 1307-1313. https://doi.org/10.1093/cercor/bhl041

[85] Hu, Y., Chen, Z., Huang, L., Xi, Y., Li, B., Wang, H., Yan, J., Lee, T.M.C., Tao, Q., So, K.-F. and Ren, C. (2017) A Translational Study on Looming-Evoked Defensive Response and the Underlying Subcortical Pathway in Autism. Scientific Reports, 7, Article No. 14755. https://doi.org/10.1038/s41598-017-15349-x 
[86] Michely, J., Rigoli, F., Rutledge, R.B., Hauser, T.U. and Dolan, R.J. (2020) Distinct Processing of Aversive Experience in Amygdala Subregions. Biological Psychiatry. Cognitive Neuroscience and Neuroimaging, 5, 291-300. https://doi.org/10.1016/j.bpsc.2019.07.008

[87] McFadyen, J., Mattingley, J.B. and Garrido, M.I. (2019) An Afferent White Matter Pathway from the Pulvinar to the Amygdala Facilitates Fear Recognition. eLife, 8, e40766. https://doi.org/10.7554/eLife.40766

[88] O’Neill, P.K., Gore, F. and Salzman, C.D. (2018) Basolateral Amygdala Circuitry in Positive and Negative Valence. Current Opinion in Neurobiology, 49, 175-183. https://doi.org/10.1016/j.conb.2018.02.012

[89] Fernando, A.B.P., Murray, J.E. and Milton, A.L. (2013) The Amygdala: Securing Pleasure and Avoiding Pain. Frontiers in Behavioral Neuroscience, 7, Article No. 190. https://doi.org/10.3389/fnbeh.2013.00190

[90] Cowey, A. (2010) The Blindsight Saga. Experiments in Brain Research, 200, 3-24. https://doi.org/10.1007/s00221-009-1914-2

[91] Ajina, S., Pestilli, F., Rokem, A., Kennard, C. and Bridge, H. (2015) Human Blindsight Is Mediated by an Intact Geniculo-Extrastriate Pathway. eLife, 4, e08935. https://doi.org/10.7554/eLife.08935

[92] Cauchoix, M. and Crouzet, S. (2013) How Plausible Is a Subcortical Account of Rapid Visual Recognition? Frontiers in Human Neuroscience, 7, Article No. 39. https://doi.org/10.3389/fnhum.2013.00039

[93] Hurme, M., Koivisto, M., Revonsuo, A. and Railo, H. (2019) V1 Activity during Feedforwards and Early Feedback Processing Is Necessary for Both Conscious and Unconscious Motion Perception. NeuroImage, 185, 313-321. https://doi.org/10.1016/j.neuroimage.2018.10.058

[94] Railo, H., Andersson, E., Kaasinen, V. and Laine, T. (2014) Unlike in Clinical Blindsight Patients, Unconscious Processing of Chromatic Information Depends on Early Visual Cortex in Healthy Humans. Brain Stimulation, 7, 415-420. https://doi.org/10.1016/j.brs.2014.01.060

[95] Jimenez, M., Grassini, S., Montoro, P.R., Luna, D.E. and Koivisto, M. (2018) Neural Correlates of Visual Awareness at Stimulus Low vs. High-Levels of Processing. Neuropsychologia, 121, 144-152. https://doi.org/10.1016/j.neuropsychologia.2018.11.001

[96] Koivisto, M. and Grassini, S. (2016) Neural Processing around 200 ms after Stimulus-Onset Correlates with Subjective Visual Awareness. Neuropsychologia, 84, 235 243. https://doi.org/10.1016/j.neuropsychologia.2016.02.024

[97] Koivisto, M., Salminen-Vaparanta, N., Grassini, S. and Revonsuo, A. (2016) Subjective Visual Awareness Emerges Prior to P3. European Journal of Neuroscience, 43, 1601-1611. https://doi.org/10.1111/ejn.13264

[98] Yorzinsky, J., Penkunas, M., Platt, M.L. and Coss, R.G. (2014) Dangerous Animals Capture and Maintain Attention in Humans. Evolutionary Psychology, 12, 534-548. https://doi.org/10.1177/147470491401200304

[99] Langeslag, S.J.E. and van Strien, J.W. (2018) Early Visual Processing of Snakes and Angry Faces: An ERP Study. Brain Research, 1678, 297-303.

https://doi.org/10.1016/j.brainres.2017.10.031

[100] Adolphs, R. (2013) The Biology of Fear. Current Biology, 23, R79-R93. https://doi.org/10.1016/j.cub.2012.11.055

[101] Servonnet, A., Hernandez, G., El Hage, C., Rompré, P.-P. and Samaha, A.-N. (2020) Optogenetic Activation of the Basolateral Amygdala Promotes Both Appetitive 
Conditioning and the Instrumental Pursuit of Reward Cues. Journal of Neuroscience, 40, 1732-1743. https://doi.org/10.1523/JNEUROSCI.2196-19.2020

[102] Contreras-Alcantara, S., Baba, K. and Tosini, G. (2012) Removal of Melatonin Receptor Type 1 Induces Insulin Resistance in the Mouse. Obesity, 18, 1861-1863. https://doi.org/10.1038/oby.2010.24

[103] Garcia-Saenz, A., Sánchez de Miguel, A., Espinosa, A., Valentin, A., Aragonés, N., Llorca, J., Amiano, P., Sánchez, V.M., Guevara, M., Capelo, R., Tardón, A., PeiróPerez, R., Jiménez-Moleón, J.J., Roca-Barceló, A., Pérez-Gómez, B., Dierssen-Sotos, T., Fernández-Villa, T., Moreno-Iribas, C., Moreno, V., García-Pérez, J., CastañoVinyals, G., Pollán, M., Aubé, M. and Kogevinas, M. (2018) Evaluating the Association between Artificial Light-at-Night Exposure and Breast and Prostate Cancer Risk in Spain (MCC-Spain Study). Environmental Health Perspectives, 126, Article ID: 047011. https://doi.org/10.1289/EHP1837

[104] James, P., Bertrand, K.A., Hart, J.E., Schernhammer, E.S., Tamimi, R.T. and Laden, F. (2017) Outdoor Light at Night and Breast Cancer Incidence in Nurses' Health Study II. Environmental Health Perspectives, 125, Article ID: 087010. https://doi.org/10.1289/EHP935

[105] Nash, T., Chow, E.S., Law, A.D., Fu, S.D., Fuszara, E., Bilska, A., Bebas, P., Kretzschmar, D. and Giebultowicz, J.M. (2019) Daily Blue-Light Exposure Shortens Lifespan and Causes Brain Neurodegeneration in Drosophila. NPJ Aging and Mechanisms of Disease, 5, 8. https://doi.org/10.1038/s41514-019-0038-6

[106] Ondrusova, K., Fatehi, M., Bayr, A., Czarnecka, Z., Long, W., Suzuki, K., Campbell, S., Philippaert, K., Hubert, M., Tredget, E., Kwan, P., Touret, N., Wabitsch, M., Lee, K.Y. and Light, P.E. (2017) Subcutaneous White Adipocytes Express a Light Sensitive Signalling Pathway Mediated via a Melanopsin/TPRC Axis. Scientific Reports, 7, Article No. 16332. https://doi.org/10.1038/s41598-017-16689-4

[107] Ratnayake, K., Payton, J.L., Harshana Lakmal, O. and Karunarathne, A. (2018) Blue Light Excited Retinal Intercepts Cellular Signalling. Scientific Reports, 8, Article No. 10207. https://doi.org/10.1038/s41598-018-28254-8

[108] Enwemeka, C.S., Bumah, V.V. and Santos Masson-Myers, D. (2020) Light as a Potential Treatment for Pandemic Coronavirus Infections: A Perspective. Journal of Photochemistry and Photobiology B: Biology, 207, Article ID: 111891.

https://doi.org/10.1016/j.jphotobiol.2020.111891

[109] Sommer, A.P. (2019) Mitochondrial Cytochrome C Oxidase Is Not the Primary Acceptor for Near Infrared Light-It Is Mitochondrial Bound Water: The Principles of Low-Level Light Therapy. Annals of Translational Medicine, 7, S13. https://doi.org/10.21037/atm.2019.01.43

[110] Allen, M. and Friston, K. (2018) From Cognitivism to Autopoiesis: Towards a Computational Framework for the Embodied Mind. Synthese, 195, 2459-2482. https://doi.org/10.1007/s11229-016-1288-5

[111] Parr, T. and Friston, K.J. (2017) The Active Construction of the Visual World. Neuropsychologia, 104, 92-101. https://doi.org/10.1016/j.neuropsychologia.2017.08.003

[112] Soares, S.C., Lindström, B., Esteves, F. and Öhman, A. (2014) The Hidden Snake in the Grass: Superior Detection of Snakes in Challenging Attentional Conditions. PLoS $O N E$, 9, e114724. https://doi.org/10.1371/journal.pone.0114724 